\title{
The origin of the Bemaraha tsingy (Madagascar)
}

\author{
Márton Veress ${ }^{1}$, Dénes Lóczy ${ }^{2}$, Zoltán Zentai ${ }^{1}$, Gábor Tóth ${ }^{1}$, Roland Schläffer ${ }^{1}$
}

\begin{abstract}
:
Veress M., Lóczy D., Zentai Z., Tóth G. and Schläffer R. 2008. The origin of the Bemaraha tsingy (Madagascar). International Journal of Speleology, 37 (2), 131-142. Bologna (Italy). ISSN 0392-6672.

On Madagascar the most representative occurrences of tsingy are at Ankarana and Bemaraha. The tsingy are built up of giant grikes developed along cracks as well as karren features of much smaller size which cover the surfaces between grikes. We investigated the Bemaraha tsingy of Madagascar (surveyed profiles, measured grike directions, etc.) in order to reconstruct their development. The observations indicate that the majority of grikes of the tsingy are created from caves formed under the karst water table and subsequently opened up to the surface. The predominant processes may have been downward progressing dissolution or the collapse of cave roofs.
\end{abstract}

Keywords: tropical karst, karren features, grikes, tsingy, Bemaraha tsingy

Received 30 April 2008; Revised 23 May 2008; Accepted 23 June 2008

\section{INTRODUCTION}

The paper is meant to explain the origin of the geomorphic features of the Bemaraha tsingy, Western Madagascar. The Tsingy, a remarkable tropical karst landform assemblage, consist of extensive fields of giant grikes perpendicular to each other. tsingy occur in four localities of Madagascar (Middleton, 2004), the most significant being the Ankarana and the Bemaraha tsingy (Fig. 1, 2).

\section{GENERAL DESCRIPTION OF THE BEMARAHA TSINGY}

The Bemaraha tsingy of $1500 \mathrm{~km}^{2}$ area is located in Western Madagascar, $150 \mathrm{~km}$ northwards the town of Morondava, along the Manambolo River, mainly on its northern bank. Little Tsingy and Great Tsingy can be distinguished. The Little Tsingy is located next to the river, while the Great Tsingy is at $8 \mathrm{~km}$ distance north of it (Fig. 1, 2).

The amount of annual rainfall here is moderately high (1000-1500 mm). The Bemaraha tsingy constitute a low, hill type karst developed on the surface of a 300$500 \mathrm{~m}$ thick Jurassic limestone sequence (Besairie

1 Department of Physical Geography, University of West Hungary, H-9700 Szombathely, Károlyi G. tér 4. HUNGARY. E-mail: vmarton@ttmk.nyme.hu

2 Department of Environmental Geography and Landscape Conservation, University of Pécs, H-7624 Pécs, Ifjúság útja 6. HUNGARY. E-mail: loczyd@gamma.ttk.pte.hu
\& Collignon, 1972). The rock is tilted along faults, therefore, the beds dip towards the west. The joints are of NNE to SSW and WNW to ESE strike. Elevation is below $200 \mathrm{~m}$ in the west but it rises to $400-500 \mathrm{~m}$ above sea level on the eastern part, where it forms a steep cuesta.

\section{LITERATURE OVERVIEW}

The Madagascar tsingy were primarily described by Duflos (1966), Rossi (1974, 1983) and Salomon (1987). Rossi (1983) presented a few characteristics of the tsingy, e.g. separate grikes and sabre-like mounts. The different expeditions mainly investigated the caves and the fauna of the tsingy karst (Duflos, 1966; Dobrilla \& Wolozan, 1994; Middleton, 1996, 1998; Dobrilla, 2006; Delaty et al., 2006). The characteristics of the tsingy were summarised by Middleton (2004) and by Grunewald \& Wolozan (2006). Researchers described karren similar to those on the Madagascar tsingy from Brazil (Tricart \& Cardoso da Silva, 1960), New Guinea (Verstappen, 1964), Sarawak (Wilford \& Wall, 1965), Tanzania and Kenya (Cooke, 1973) and Western and Eastern Australia (Grimes, in press). According to Rossi (1983) the Ankarana tsingy developed as a result of direct rainfall on very well bedded, partially crystalline and pure limestone with low porosity and a system of sparse but massive joints/faults. According to Rossi (1974) the intensity of the rainfall is also important for tsingy development. Intensities 


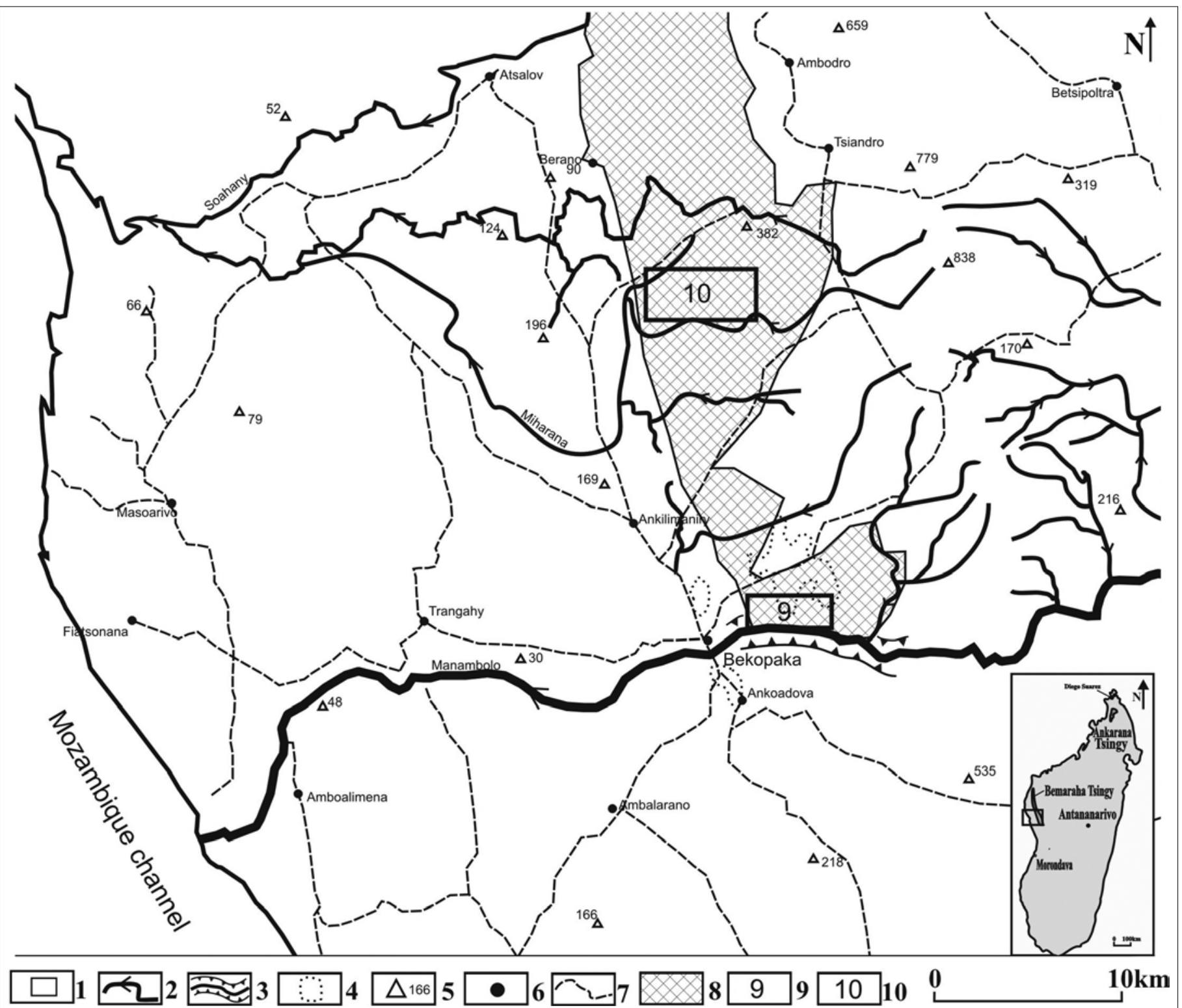

Fig. 1. The map of the region of the Bemaraha tsingy. Legend: 1. area presented in detail, 2. river, 3. gorge, 4. swamp, 5. summit and altitude above sea level, 6. settlement, 7. road, 8. National Park, 9. Little Tsingy, 10. Great Tsingy

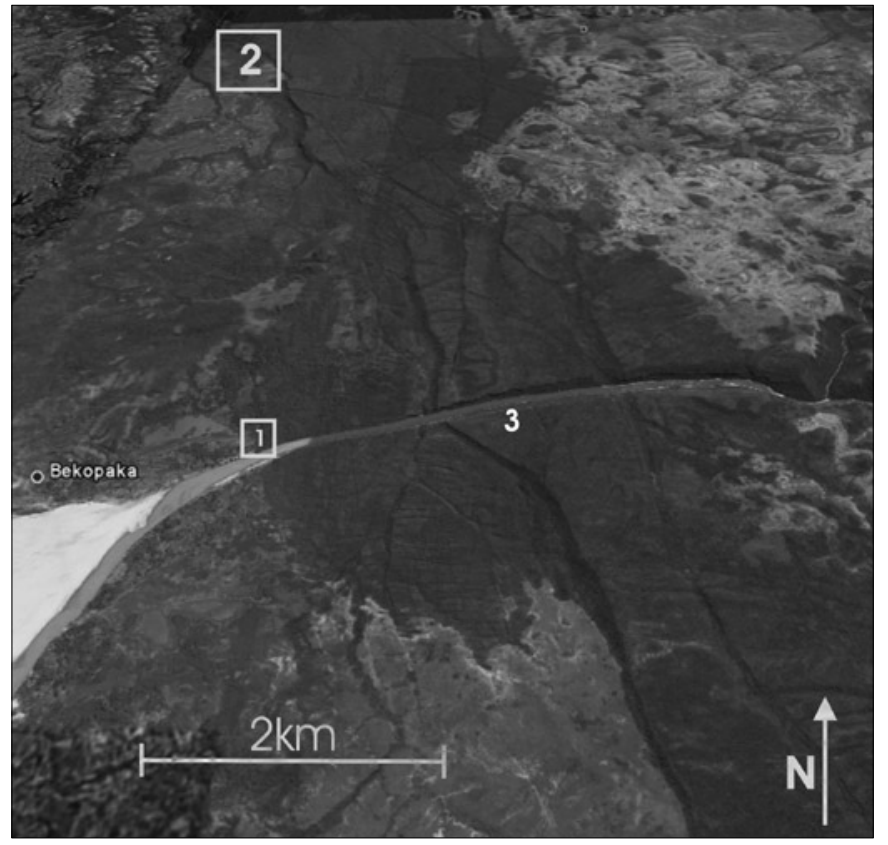

Fig. 2. Satellite image of the Bemaraha tsingy. Legend: 1. Little Tsingy, 2. Great Tsingy, 3. River Manambolo of $105 \mathrm{~mm} \mathrm{~h}^{-1}$ and $350 \mathrm{~mm}$ in 24 hours could be measured on the Ankarana tsingy today. The relative significance of the processes which contributed to tsingy formation are still debated. Rossi (1974, 1983) and Balázs (1980) both claim that rainwater dissolves barren rock and infiltrates along joints, widening them into grikes. According to Salomon (1987) the tsingy develop under soils and regolith and with the gradual removal of soil it is becoming uncovered. Delaty et al. (2006) emphasize that grike development is associated with the destruction of a former cave system. The development of tsingy by opening towards the surface of shallow caves is also reported from Bullita cave in Australia (Audra, pers. comm.). The morphological study of the Bemaraha tsingy was meant to clarify some issues concerning tsingy development.

\section{METHODS}

- For the survey of landforms in the study area we determined geographical coordinates (elevation and location) on the tsingy using GPS. 
- We measured the alignments of 116 grikes. Classifying the data into categories of regular interval the frequency of distribution for grike alignment was calculated (Fig. 3).

- We measured the morphometric parameters (width and depth) of the grikes and set up categories of regular interval, for the parameter values (Fig. 4). However, we cannot provide a frequency distribution curve for the depths of grikes on the Bemaraha Great Tsingy since we lacked the instrumentation necessary for exact measurements and reliable data could only be obtained for shallow grikes.

- We surveyed cross-sections, planforms and longitudinal profiles of grikes and caves of the Bemaraha tsingy. The generalised representations of the thus constructed profiles (Fig. 5, 6) allow us to suggest a typology for the karren features of the tsingy.

\section{RESULTS OF MORPHOLOGICAL SURVEY}

\section{Large-scale karst landforms}

Although its grikes also divide the surface into clints (Fig. 7,8 ), the Bemaraha tsingy are a special tropical karst area. The grikes here are larger than those of the Ankarana tsingy: those of the Little tsingy are mostly 1-3 m wide (but grikes of 5 and even $8 \mathrm{~m}$ width also occur) and their depths range between 5-20 m (Fig. 4). The grikes of the Great Tsingy are mostly deeper (80-120 m - Fig. 9) than those of the Little Tsingy, their width is from a few metres to some tens of metres. As it has already been mentioned, grikes in both subdivisions of the Bemaraha tsingy are aligned along the two joint directions perpendicular to each other (NNE to SSW and WNW to ESE, Fig. 3.a, b, 8). The Manambolo River cuts through the area and opened up a range of joints widened to grikes and cave passages observable everywhere along the steep walls of the river gorge:

- The rock roofs of caves are either free of joints or fractured or dismembered by narrow grikes (of a few centimetres width).

- Grikes which develop downwards from the surface also occur next to caves without joints at the same level. Similar grikes are also observed without caves. Their depths vary greatly.

- For spatial arrangement the grikes can be perpendicular or oblique, narrowing down towards their bottoms, which are lined with large caved-in fragments.

- Finally, single grikes can be partially or totally infilled with calcareous concretions. False cave ceilings of sinter precipitation (or of rock fragments cemented by sinter), observed at different levels, are remnants of cave fills.

Some grikes show simple cross-sections, while others are composite (Fig. 5). Simple grikes can be narrowing down from the surface downwards (Fig. 5e), or widening (Fig. $5 \mathrm{~b}$ ) or can show uniform width (Fig. 5d). Grikes narrowing downwards are particularly common in the higher sections of the Great Tsingy. Among composite grikes the type which is narrow at the top and wide at the bottom and has oval crosssection is the most widespread (Fig. 5a, 5b, 5c, 5f). The morphology is different at different sections of the grikes (see below). A grike on whose bottom a smaller channel developed also belongs to this type (Fig. 5a). The walls are often overhanging and have rock cave debris (Fig. 5b), and allochthonous fine sediment of various origin (Fig. 5d), and soils occur on their floors. Locally, in the vicinity of the river, gravels and sands are deposited on the Little Tsingy. Calcareous precipitations in larger amounts are mostly found in the grikes and caves of the Great Tsingy. False cave ceilings may also be formed of calcareous tufa and their partial destroyed remnants were also observed (Fig. 6d). Grikes may widen into cave passages (Fig. $5 \mathrm{~g})$. In this case natural bridges develop from partially destroyed roofs (Fig. 5, 10), crossed by pits or divided into blocks of collapse fragments. Former roofs are sometimes only indicated by fragments wedged between the walls. The grikes are wider apart here than on the Ankarana tsingy. We can estimate their distance at 10-15 $\mathrm{m}$ on the Little Tsingy and 15-30 m on the Great Tsingy.

As far as terminology and typology are concerned, Ford \& Williams (1989, 2007) distinguished the following assemblages of tropical karren: Karrenfeld, pinnacle karst (including stone forest), and corridor karst (including labyrinth karst). The Ankarana and the Bemaraha tsingy do not belong to the same type since they differ in morphology, size, and development. While a variety of karren features dominate the Ankarana tsingy, great grikes prevail overall on the Bemaraha tsingy.

According to Salomon (2006) the Bemaraha tsingy constitute a special subtype of tropical karst as opposed to a stone forest. Concluding from their features and development, we think that the Ankarana tsingy are tropical karren assemblages and - agreeing with Salomon (2006) - we consider the Bemaraha tsingy a typical tropical karst complex. Surface features in stone forests and on the tsingy are partially different. Stone forests are dominated by pinnacles - which also occur in tsingy areas. On the tsingy, however, mainly grikes with clints are found (Ford \& Williams, 2007). The tsingy also show karren features in greater variety and size (see below) than stone forests. We also observed narrow ridges on the Little tsingy of Ankarana and caves of various size are also typical of the Bemaraha tsingy.

\section{Karren features}

The surface of the clints is dissected by karren forms which developed on uncovered surfaces. The most characteristic karren forms here are series of rills, different types of rinnenkarren (simple runnel, decantation runnel, stepped runnel), kamenitzas (simple, composite, and uvala kamenitzas), rainpits, meandering karren, blade ridges (with rillenkarren) and pits. The above enumerated karren forms of the Bemaraha tsingy are considerably larger than those of the Ankarana tsingy: e.g. one runnel of the Great tsingy was found more than $10 \mathrm{~m}$ deep (with width less 

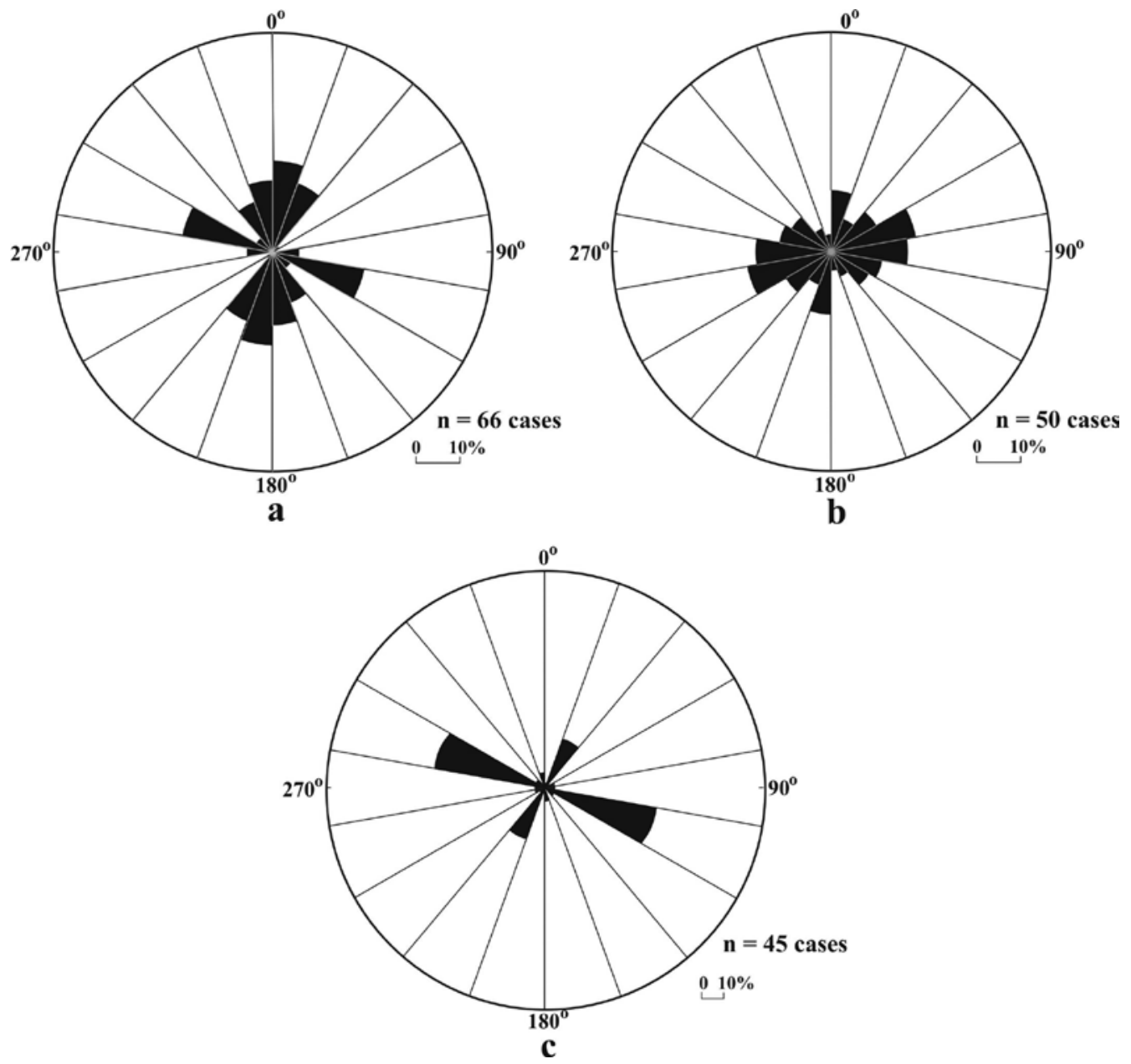

Fig. 3. Frequency distribution of grike directions on the Bemaraha Little Tsingy (a) Great Tsingy (b) and frequency distribution of axes of passages for the Anjohy Tsilika Cave (c)

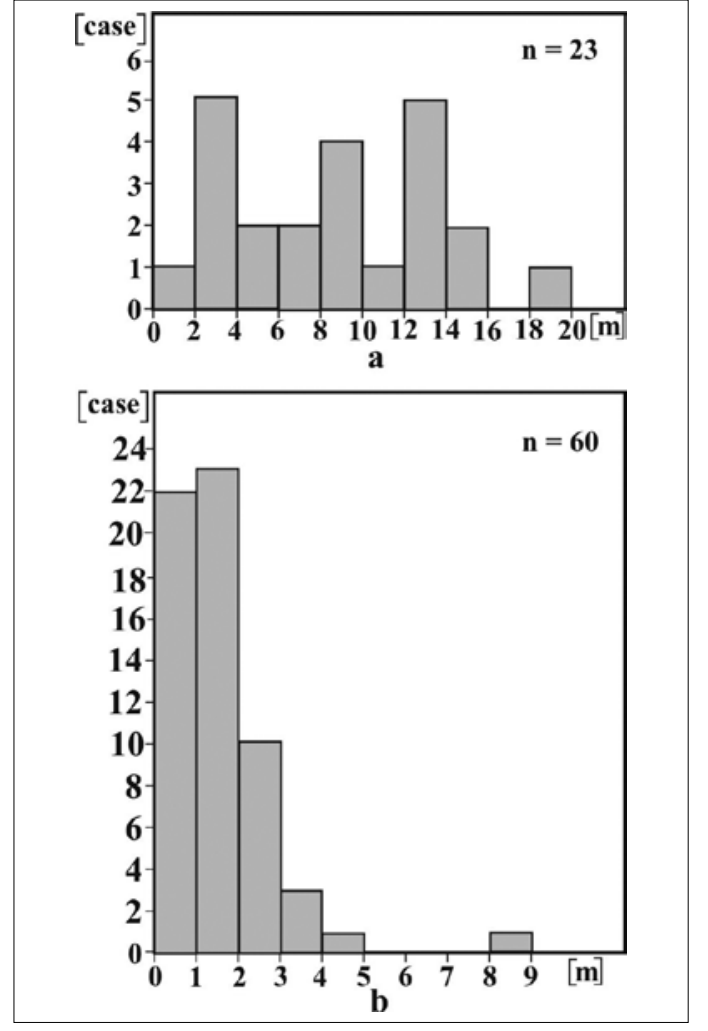

Fig. 4. Frequency distribution of the depth of grikes (a) and of the width of grikes (b) on the Bemaraha Little Tsingy

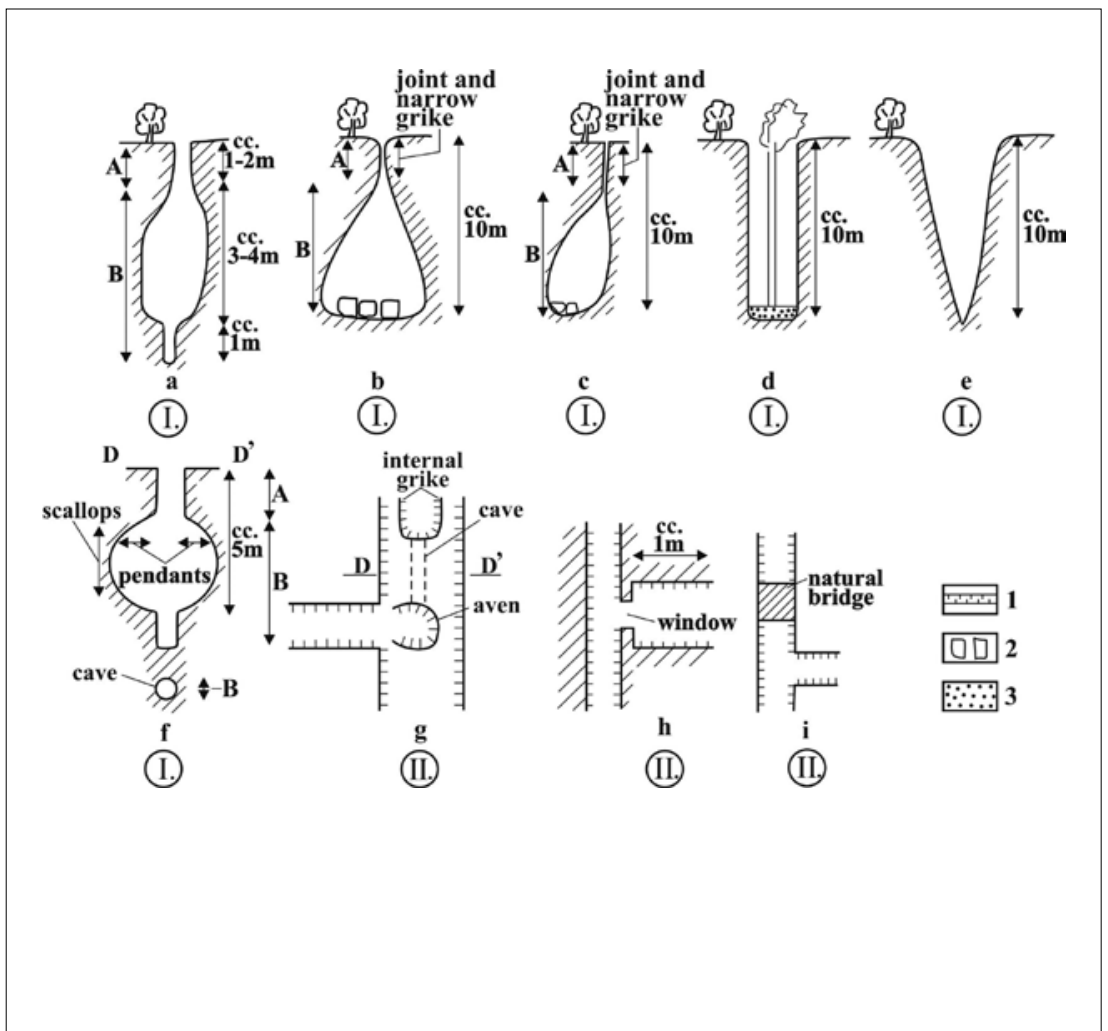

Fig. 5. Cross-sections (I) and planforms (II) of grikes on the Bemaraha Little Tsingy Legend: A: grike section formed by rainfall, B: grike section formed under karst water table, 1. cave planform, 2. cave debris, 3 . fine-grained sediment transported into the grike 


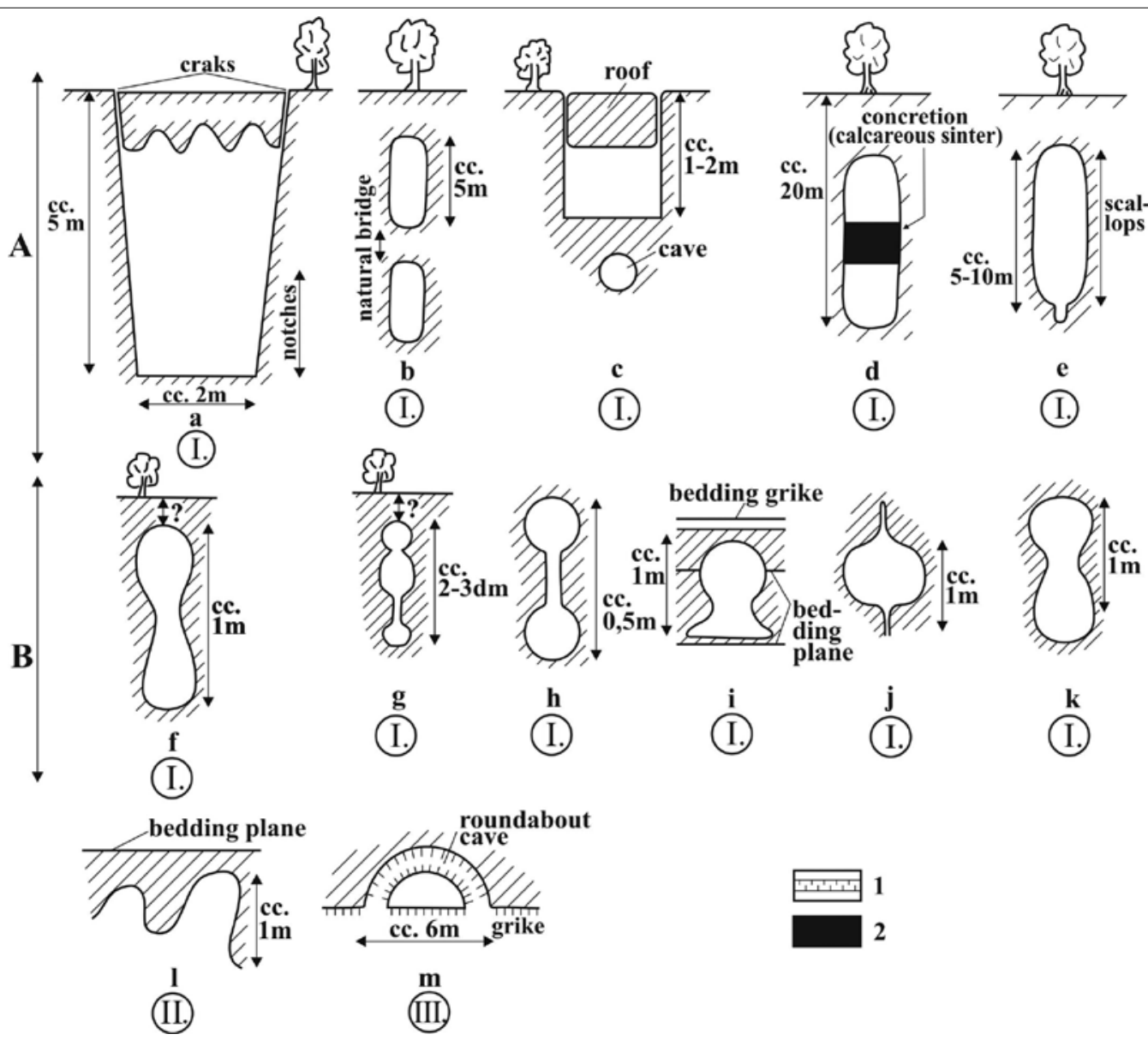

Fig. 6. Cave cross-sections (I), longitudinal profiles (II), and planforms (III) for the Bemaraha Little Tsingy. Legend: A. cross-sections of caves, B. of hanging caves, 1 . cave planforms, 2 . calcareous sinter

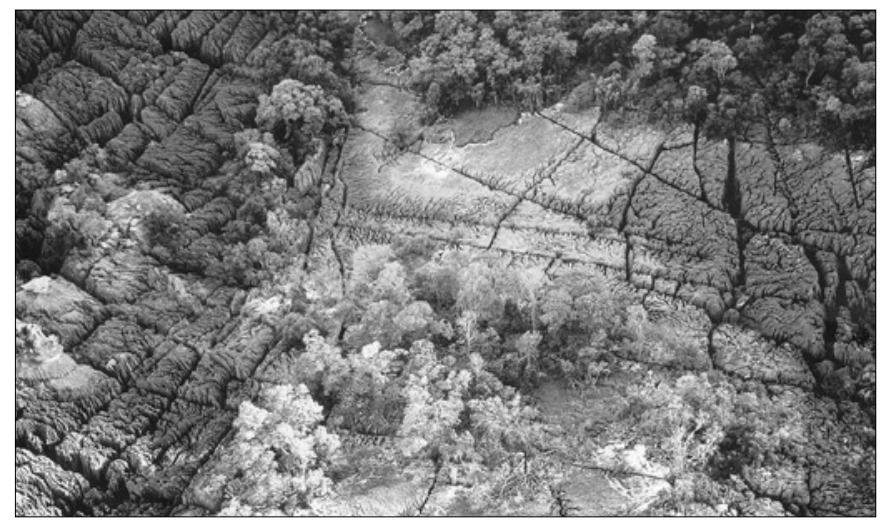

Fig. 7. Helicopter image of part of the Bemaraha tsingy (from Delaty et al. 2006)

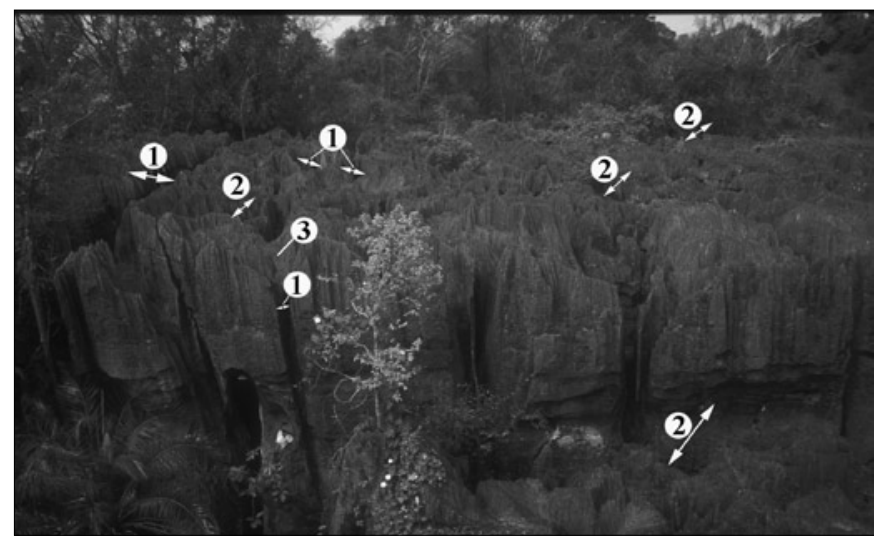

Fig. 8. Grike systems on the Bemaraha Little Tsingy. Legend: 1. grikes with WNW-ESE alignment, 2. grikes with NNE-SSW alignment, 3. natural bridge

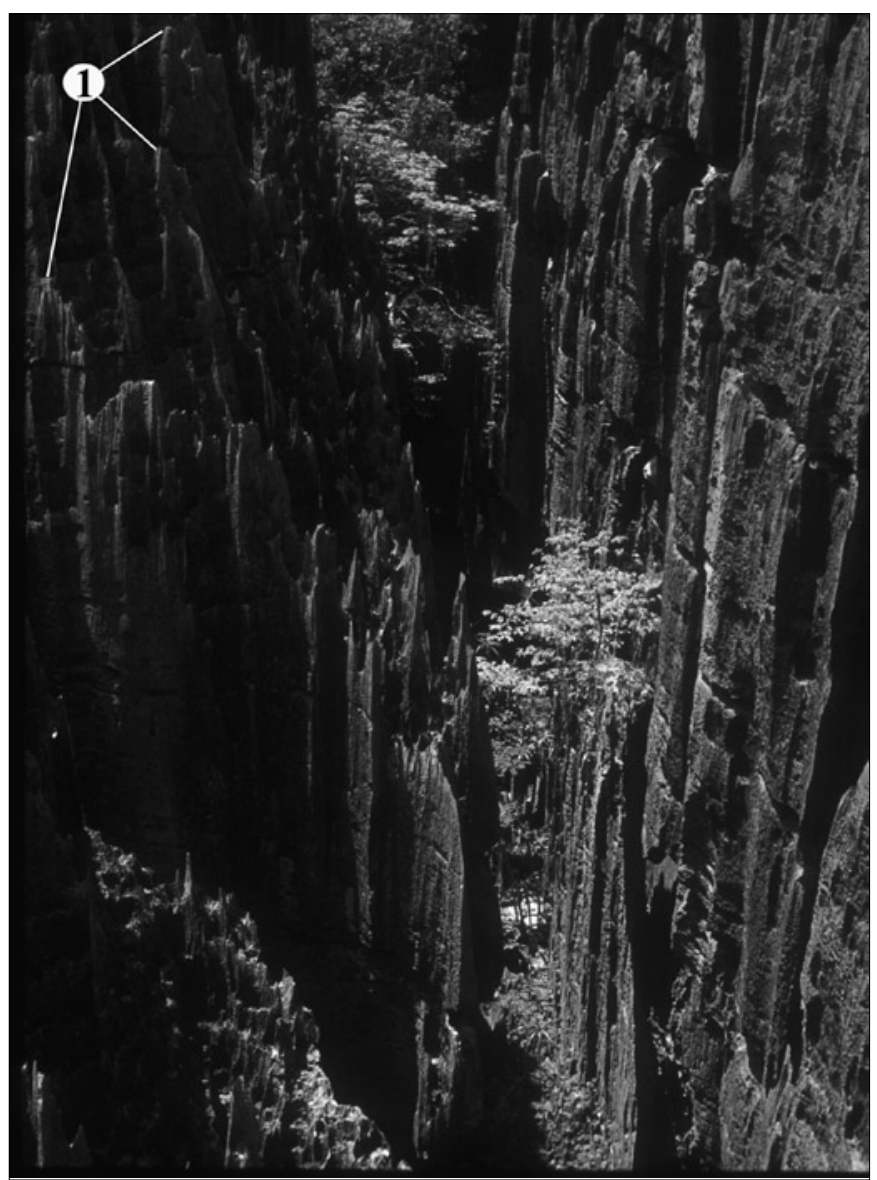

Fig. 9. The largest grike of the Bemaraha Great Tsingy. Legend: 1. pinnacles 
than $1 \mathrm{~m}$ ) and the rises of the steps on its floor are 1-2 $\mathrm{m}$ high. From inside the runnel is also dissected by rillenkarren, rainpits and kamenitzas. Pinnacles rise on the clints or some clint blocks are dismembered into pinnacles.

The features of the walls of the grikes vary according to their origin. In addition to karren formed directly by rainfall, like those on clint surfaces (rainpits, Spitzkarren, rillenkarren, runnels), there are features which only occur in grikes. They result from rainwater flowing down on grike walls. Such forms can be classified as Wandkarren and/or half-pits (with small scallops), and on gentler grike walls as kamenitzas (called 'cups' by Wilford \& Wall [1965] - Fig. 11) and these occasionally also occur on clint surfaces. The cups are aligned one another in a step-like manner. They are either independent from each other or linked. Rainpits occur on their bottoms. According to Wilford $\&$ Wall (1965) cups develop when decantation runnels connect rainpits. The water which runs out of the higher-lying cup feeds the cup below.

\section{Caves and passages}

There is another group of features not produced by rainwater (Fig. 12). Caves of various size develop under the floors of some grikes: they have lengths of some tens of metres up to some kilometre. A few metre long connecting passages are frequent between grikes (Fig. $5 g)$. The caves may link two parts of the same grike or two different grikes - as described from other karst regions (for instance, from the River Fanning karst area of Australia - Grimes, in press). Further caves in grike walls are hanging caves of circular or keyhole cross-section located a few metres above the bottom (Fig. 6f-k), 'roundabout passages', and grikes along bedding planes. 'Roundabout passages' (Fig. 6m, 13) have two entrances on the wall of the grikes and are arcuate in planform. Grikes along bedding planes equally occur on cave walls and on the walls of major grikes of a few metre depth and a few decimetre height (Fig. 14). Neighbouring grikes are often connected by bedding plane grikes. Dissolution windows (Fig. 5h), less than metre across, develop where the dividing walls were pierced by dissolution. Calcareous precipitations occur in the form of sinter and dripstones both in grikes and caves. The calcareous sinter produces cave fills or false roofs (Fig. 6d). Common speleothems are coatings, flowstones, balcony stalagmites, stalactites, and botryoids. Scallops of a few decimetre size are also observed on the walls of both grikes (Fig. 15) and caves. Locally they occur isolated, elsewhere in pairs or groups at several levels usually on grike walls higher than one metre from the bottom. The sizes of the notches (Fig. 16) are rather variable: their height is a few decimetres, whereas their depth ranges from a few decimetres to several metres - similarly to bedding plane grikes. They are not contiguous as notches of ca 10-30 metre length wedge out only to appear again on the walls, both of caves and of hanging caves.

The horizontal caves of the Bemaraha tsingy of oval or circular cross-section developed under the karst water table (Fig. 6b, 6d-e, 6f-k). Such are passage

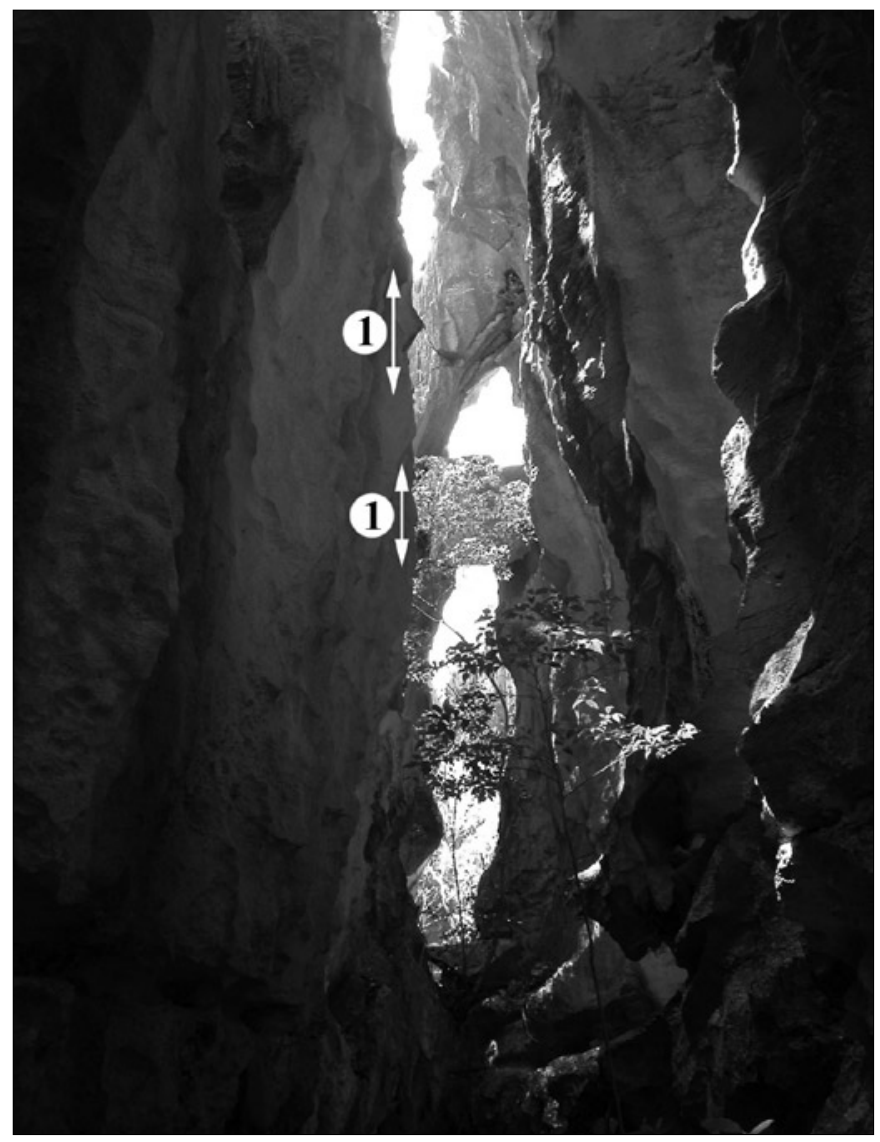

Fig. 10. Natural bridge on the Bemaraha Little Tsingy. Legend: 1. natural bridge

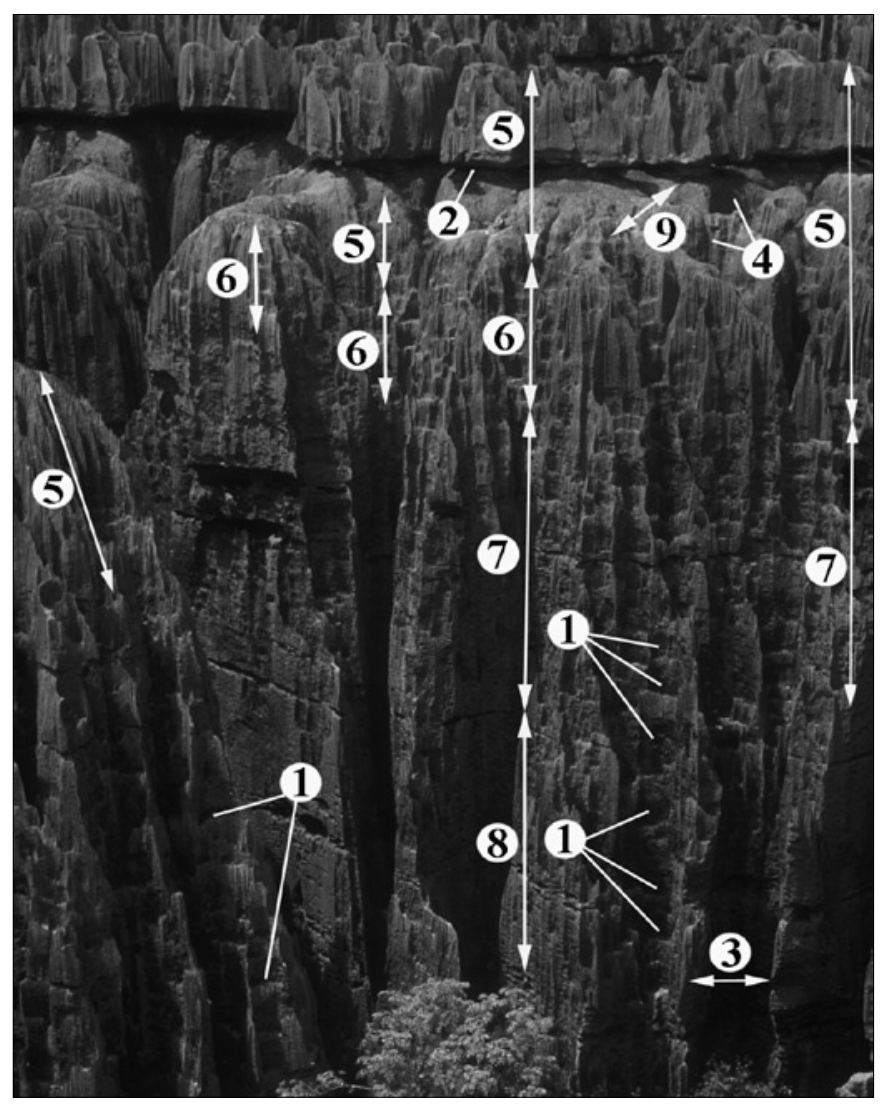

Fig. 11.Cups from the Bemaraha Great Tsingy

Legend: 1 . cups, 2 . bedding plane grike formed by percolating waters, 3. half pit or grike, 4. pit, 5. zone of rillenkarren, 6 . zone of rillenkarren and cups, 7. zone of cups, 8. zone of rillenkarren (with scallops) and cups, 9. bedding plane developed through bed scarp retreat 


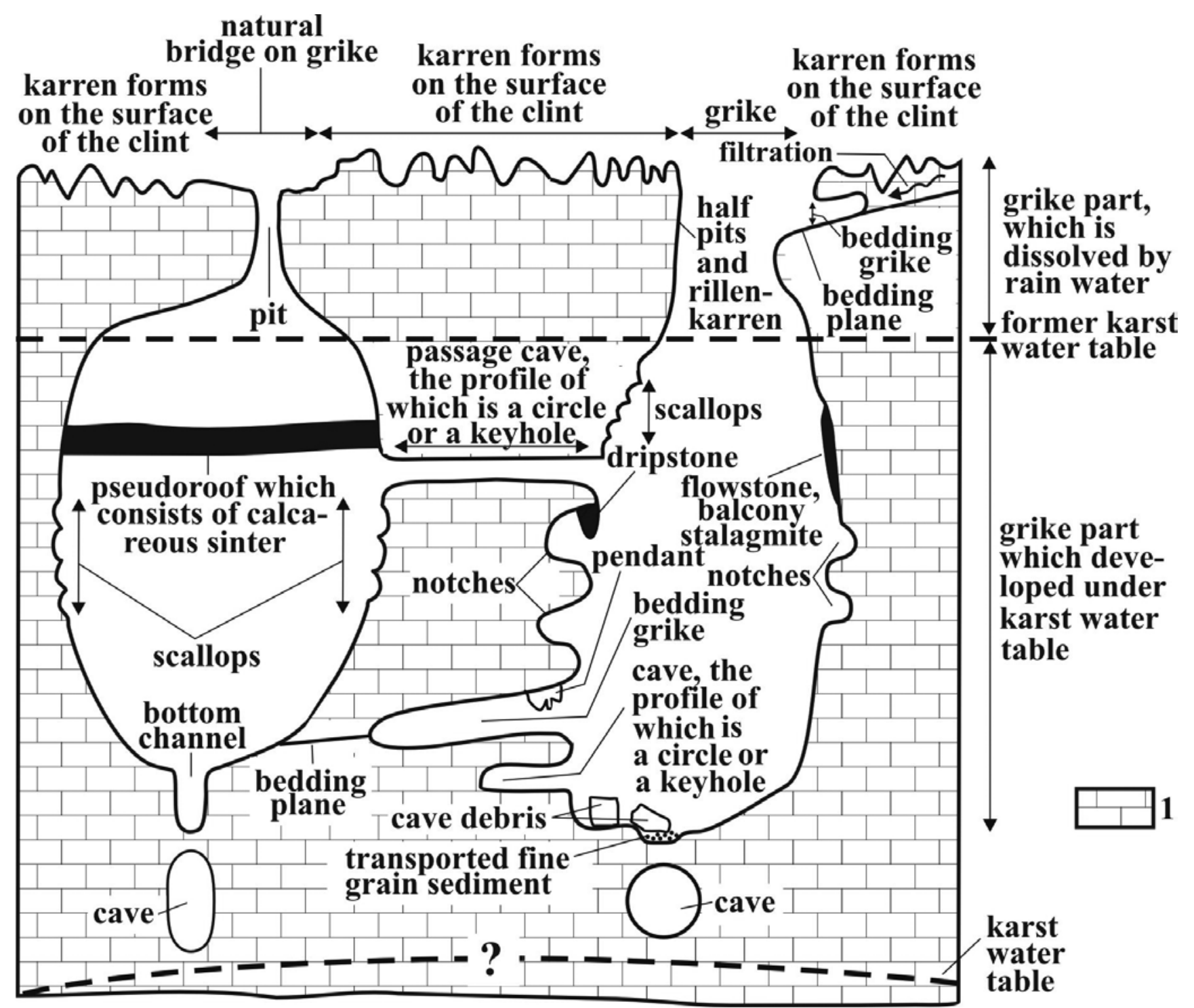

Fig. 12.Generalized morphological profile of the grike walls of the Bemaraha tsingy. Legend: 1. limestone

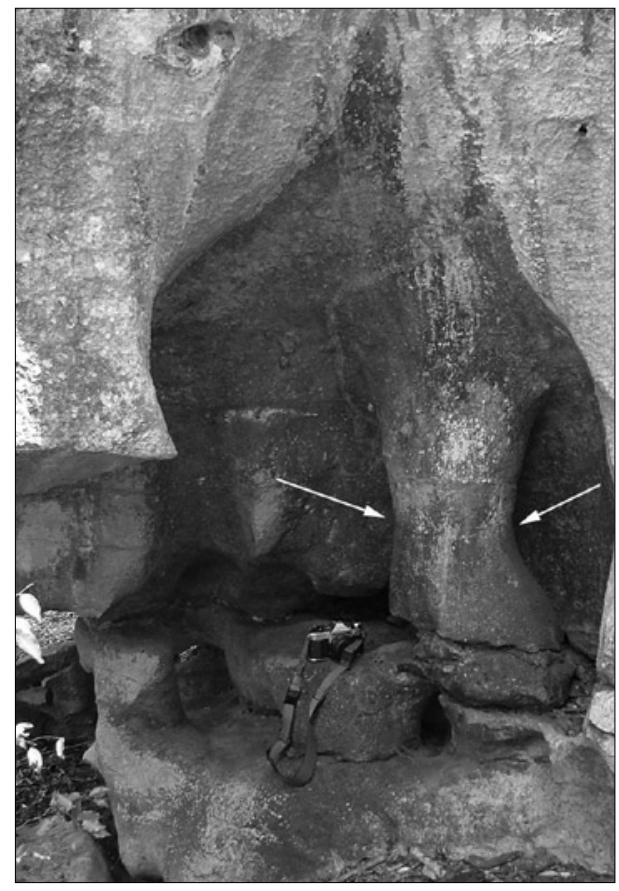

Fig. 13. 'Roundabout' cave (shown by arrows)

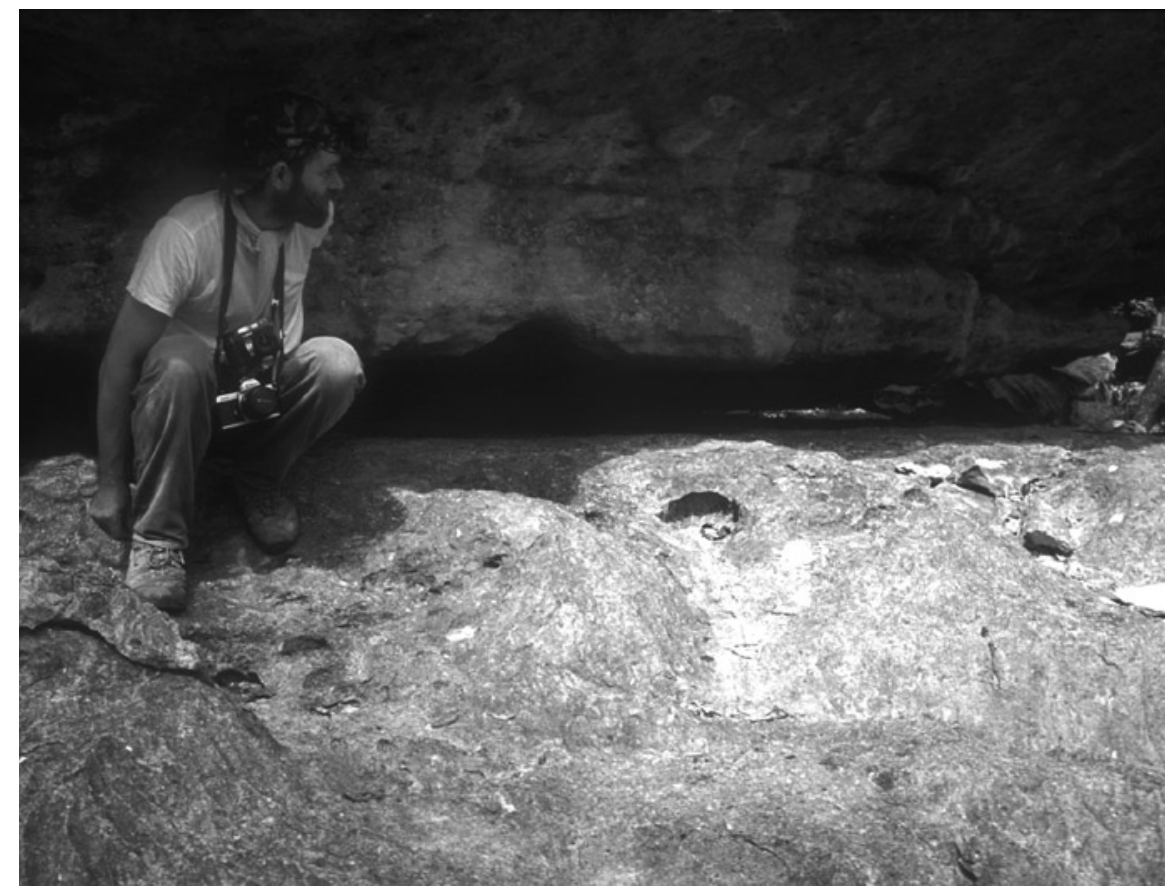

Fig. 14. Bedding plane grike from the Bemaraha Great Tsingy 


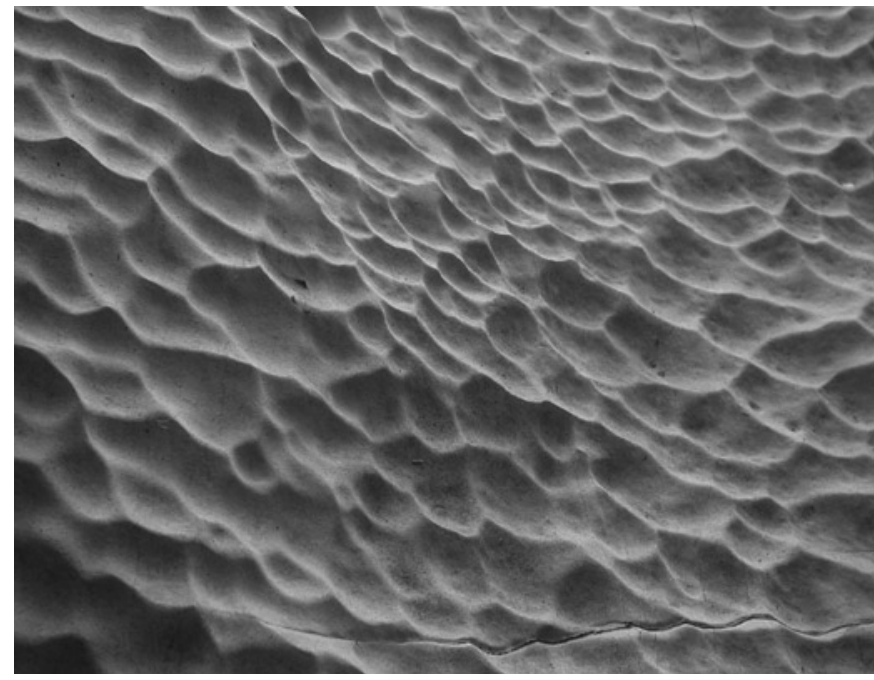

Fig. 15.Scallops on a grike wall (Great Tsingy)

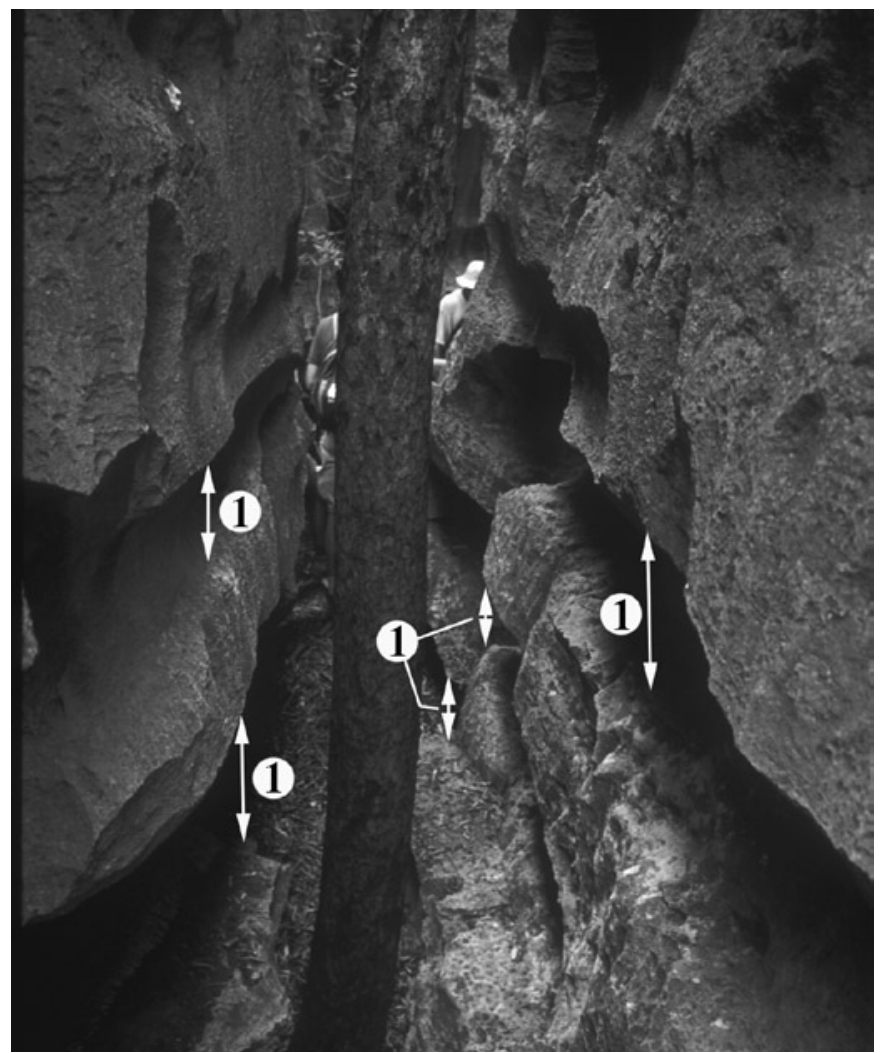

Fig. 16.Notches on the grike walls from the Bemaraha Little Tsingy Legend: 1. notches

caves of various length connecting grikes and caves communicating with River Manambolo. They are by now non-active remnants of the joint-controlled phreatic network.

\section{DEVELOPMENT OF THE BEMARAHA TSINGY}

\section{Evaluating morphological evidence}

The study of the individual caves (Fig. 5f) and extensive cave systems (Fig. 17) and the comparison of their morphometry with the pattern of grikes allow certain conclusions for the origin of the tsingy. It was observed that the pattern of cave systems is identical with that of the grikes: the caves are parallel with or perpendicular to each other. For instance, the frequency distribution of grikes on the Little Tsingy is similar to that of the passages of the Anjohy Tsilika cave (Fig. 2). The forms of caves also resemble the narrow and high forms of grikes (Fig. 6a-e). The similarity in form and the fact that caves occur next to grikes prove that the grikes were caves once.

Further remnants of the phreatic network are passage caves, natural bridges, hanging caves, 'roundabout caves', and bedding plane grikes (complex and downward widening grikes). Since they do not show overhanging walls, the grikes are not products of infiltrating rainwater. Rainwater will be saturated after percolating few metres into the rock. Solutional windows are evidence for horizontal dissolution. Surface water flow cannot produce such features since such waters of low solubility cannot widen joints into a dense and labyrinth-like grike system. Since only dissolution features are found on grike walls, their erosional origin can be excluded. This seems confirmed also by the fact that grikes are interconnected by passage caves. Hanging caves, 'roundabout caves', and bedding grikes may occur on grike walls because the grikes belonged to the former phreatic network. Branches of the network developed into hanging caves, 'roundabout caves', and bedding plane grikes on grike walls.

The natural bridges and blocks along the upper margins of complex grikes indicate cave collapse. The grikes were former caves because the crosssections of their lower parts are oval (Fig. 5c, $5 f)$, similarly to phreatic caves. Another piece of evidence are pendants, a few decimetres high spires on cave roofs and passage caves as well as on the parts of the hanging grike walls. Pendants develop in caves where deposition of sediments shields the bottom from corrosion and erosion and forces water to dissolve only along the roof producing ceiling channels whose dividing ridges are later disrupted by dissolution (Bretz, 1956; Renault, 1968; Slabe, 1995).

Having accepted that the grikes developed from caves, we can explain the existence of notches and scallops on grike walls. Since notches and scallops in caves are formed by dissolution of flowing water (Slabe, 1995), those now in grikes could develop in a cave environment. The scallops of grike walls are elongated along the alignments of grikes. This fact may not only prove the action of flowing water but also that water movement followed the direction of grikes.

In downward widening grikes, where natural bridges and boulders are absent from the upper part, features (such as rillenkarren) resulting from rainwater percolation occur. Consequently, the present shapes of such grikes can be explained in the following manner:

- The roof of the former cave collapsed. This is indicated by the presence of collapse features in the upper sections, while at lower levels, forms developed under the karst water level predominate.

- The former cave coalesced with a grike developed downwards from the surface. Higher situated features were produced by rainwater, while those at 


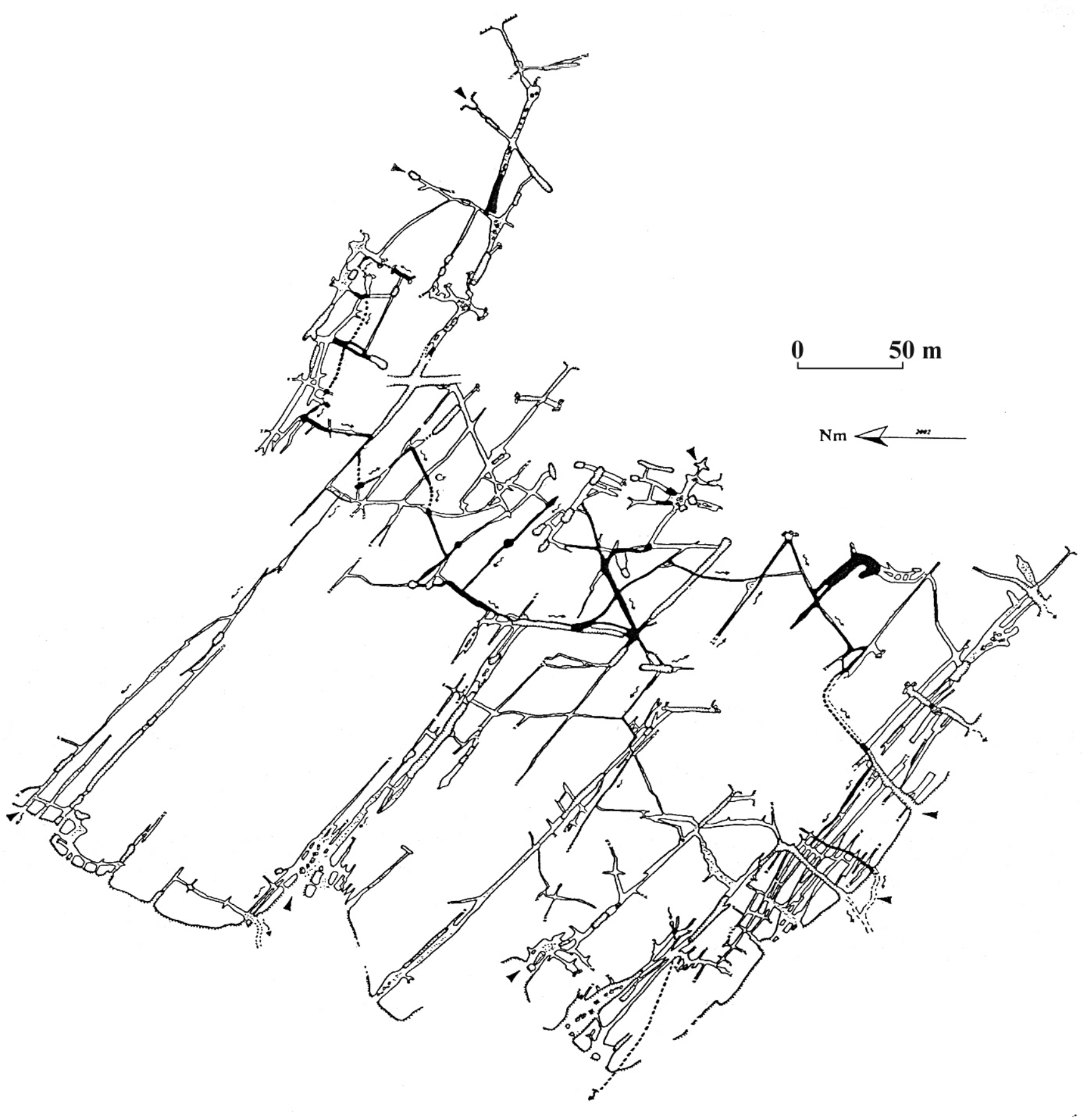

Fig. 17. Map of the Anjohy Tsilika Cave (after Dobrilla 2006)

lower levels developed under the karst water table.

Thus, we claim that the grikes result from dissolution progressing downwards from the surface. This dissolution took place either on the bare surface or under soils. Soil is preserved on grike floors favouring further deepening. In addition, soil is transported to the bottom of the grike from neighbouring clints. Since the vegetation in deep grikes can receive sufficient light, the acids and the stress produced by roots contribute to solution. Grikes developed such a way are narrowing downwards. Forms which develop under the karst water table are absent from their walls but those produced by rainfall and subsoil solution are occasionally present (minor cavities of irregular shape).

Therefore former phreatic networks were created by horizontal water flow in the shallow phreatic zone. This zone could not be at great depth below the surface. The upper, not overhanging sections of complex grikes in the Little Tsingy show 1-2 $m$ vertical extension. It seems logical that these sections of the grikes were formed by infiltrating rainwater, while those deeper than 1-2 m below the present surface developed under the karst water table. Therefore, the former karst water table in the Little Tsingy was at most 1-2 $\mathrm{m}$ deeper than the surface at that time.

Consequently, formerly a phreatic network existed in the Bemaraha tsingy, whose various parts have 
been modified. The transformation took place following the destruction of some sections of the phreatic network.

\section{Reconstruction of Tsingy development}

The base level of erosion for the Bemaraha tsingy is the River Manambolo, which borders the tsingy on the south. Therefore, the River Manambolo controls the elevation of the karst water table. When the river valley partly crossed the tsingy, the karst water table lie just below the surface and affected the tsingy. It could not have been otherwise because in the dry season the relative altitude of the highest point of the surface of the tsingy (190 m above sea level) is only $140 \mathrm{~m}$ above the present-day low-water level of the river $(50 \mathrm{~m})$. A shallow karst water table is also indicated by the ponding of water on the surface where a grike of the Little Tsingy widens to form a chamber. The bottom of this basin is only $10 \mathrm{~m}$ below surface. Here the karst water table corresponds to the low-water level of the river. Fluctuations in water level are recognized on the walls of the basin as discoloured horizons. The discolouration levels may also indicate that karst water appears locally on grike bottoms during the humid season.

The development of the tsingy may be influenced by Quaternary sea level oscillations. During glaciations the karst water table may have sunk with sea level. Therefore, lower sections of the phreatic network under the grikes of the tsingy could have extended to the former sea level. Thus, the water of the River Manambolo (then at higher level) could penetrate into the karst system. Then the River Manambolo did not function as the base level of the tsingy but recharged the phreatic network.

How can we explain the extensive dimensions of grikes? How could the depth of the grikes of the Great Tsingy several times exceed those of the Little
Tsingy?

The remarkable vertical extension of grikes is caused by major changes in the karst water table (Fig. 18). Since dissolution is most intense near the karst water table, sinking karst water table intensified dissolution on the floors of grikes and the deepening of former cave passages. The causes of sinking karst water table could be the following:

- Due to river incision the base level of erosion and simultaneously the karst water table sank. The river has hardly a valley downstream its gorge across the tsingy. The relief is merely $10 \mathrm{~m}$ between the present-day water level and the surrounding surface. Consequently, river incision - and therefore the drop of the karst water table - could not exceed $10 \mathrm{~m}$. Thus, river incision could contribute to the sinking of the karst water table and to the deepening of the former caves to some extent.

- The karst water table fluctuated. The rate of fluctuation could have been and can be very significant over the year. According to Balázs (1980) $710 \mathrm{~mm}$ rain falls during the four months of the humid season out of the annual amount of $780 \mathrm{~mm}$ for the town of Morondava.

- The extreme river regime may also add to the fluctuation of the karst water table.

- Finally the above-mentioned sea level changes could contribute to the oscillation of the karst water table.

The karst water table rose as a consequence of high rainfall and river flooding and a remarkable epiphreatic zone could develop and survive. Cave development took and takes place in the epiphreatic zone under conditions of rising karst water table. During the arid period solution and cave development is relocated into the phreatic zone below the lower karst water table. The development of the former caves happened in the epiphreatic and phreatic zones. The lower boundary

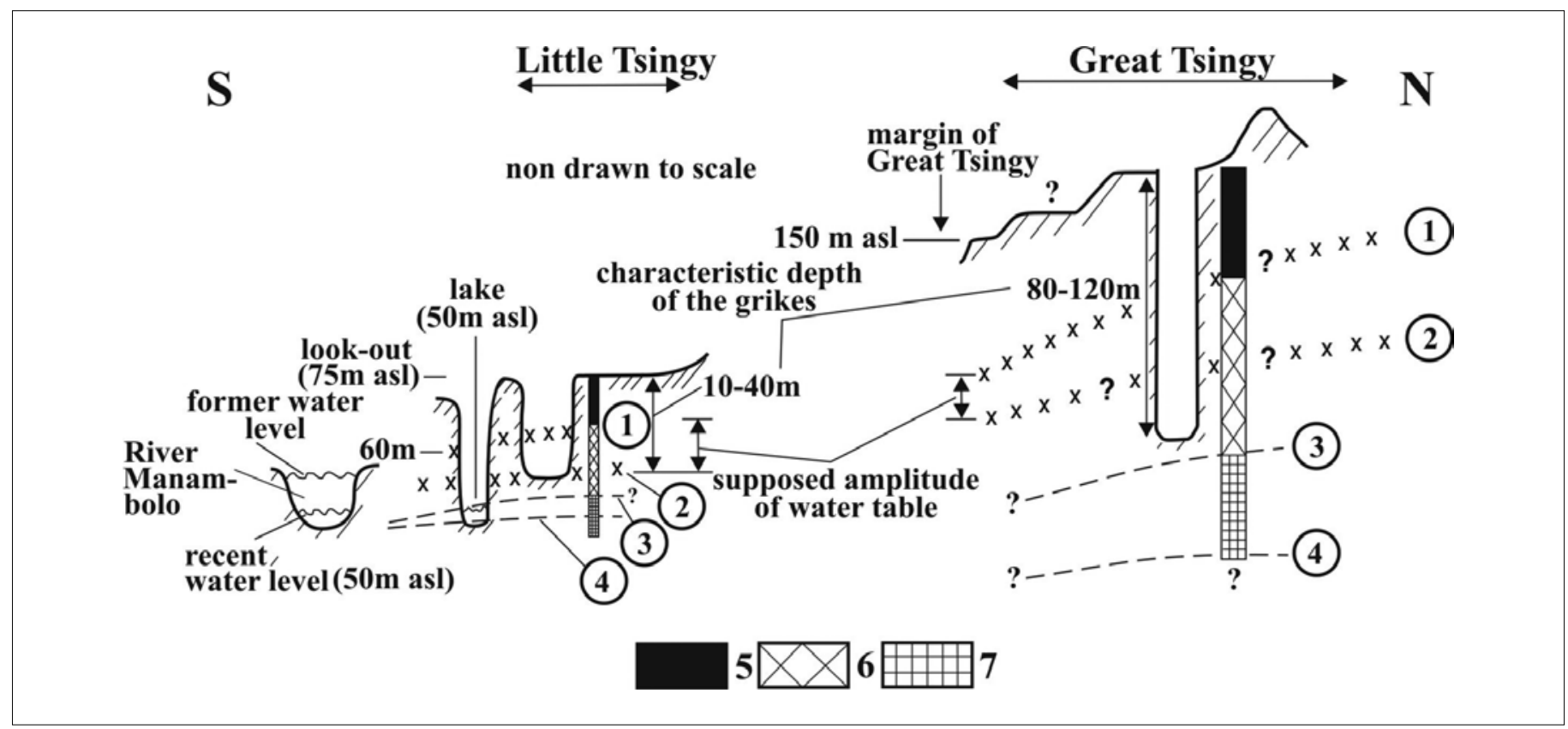

Fig. 18.Zones of solution on the Little Tsingy and Great Tsingy. Legend: 1. former upper karst water table, 2. former lower karst water table, 3. upper karst water table at present, 4 . lower karst water table at present, 5 . solution from the direction of the surface and collapse, 6 . former solution under the karst water table, 7. recent solution under the karst water table 
of the former phreatic zone is unknown.

We can explain the large vertical extension of the grikes (former caves) of the Great Tsingy with two facts (Fig. 18):

- The fluctuation of the karst water table is larger on the Great Tsingy than on the Little Tsingy, because the Great Tsingy is located farther away from the base level.

- The development of former caves also spread to the phreatic zone in the Great Tsingy.

Drawing on the above facts the following types of grike development are observed in the Little Tsingy (Fig. 19):

- The water which infiltrates downwards along cracks forms grikes (Fig. 19a $a_{1}$ ).

- A cave developed in the epiphreatic zone extends by upward dissolution, while a grike deepens downwards from the surface. Both merge and the cave opens up (Fig. 19b $b_{1}$.

- As its roof becomes thinner and thinner, the cave developed in the epiphreatic zone collapses (Fig. $19 c_{1}$ ).
- A cave results from dissolution in the epiphreatic zone. Its roof can be thicker if the highest karst water table remains at considerable depth below the surface. (The highest level of the karst water table marks the position of the cave ceiling because dissolution is only possible under the karst water table.) Therefore, the cave does not open up to the surface (Fig. 19d d $_{1}$.

On the Great Tsingy the development of the grikes could have taken the following course (Fig. 19):

- Two or more caves developed in the epiphreatic zone. Then these forms merged through solution and developed upwards until they coalesced with a grike which developed downwards. The cave opened up (Fig. 19a $a_{2}$.

- Caves developed both in the epiphreatic and phreatic zones. These became linked to each other, their roof collapsed and they opened up (Fig. 19b ) $^{2}$.

- Caves developed both in the epiphreatic zone and phreatic zones. They were merged by solution, developed upwards until they opened to the surface (Fig. $19 \mathrm{c}_{2}$ ).

- Caves developed in the epiphreatic zone and solution from direction surface

(1) $\times \times \times \times$

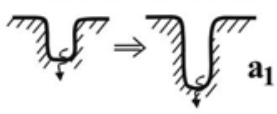

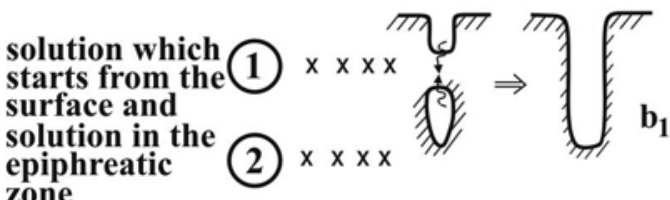
zone

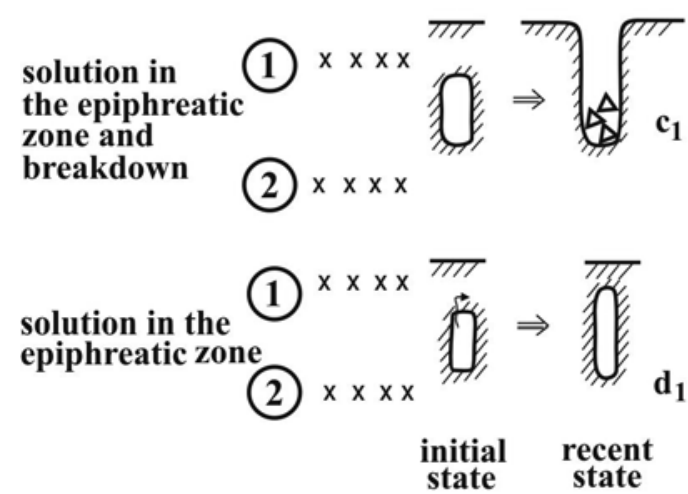

Little Tsingy

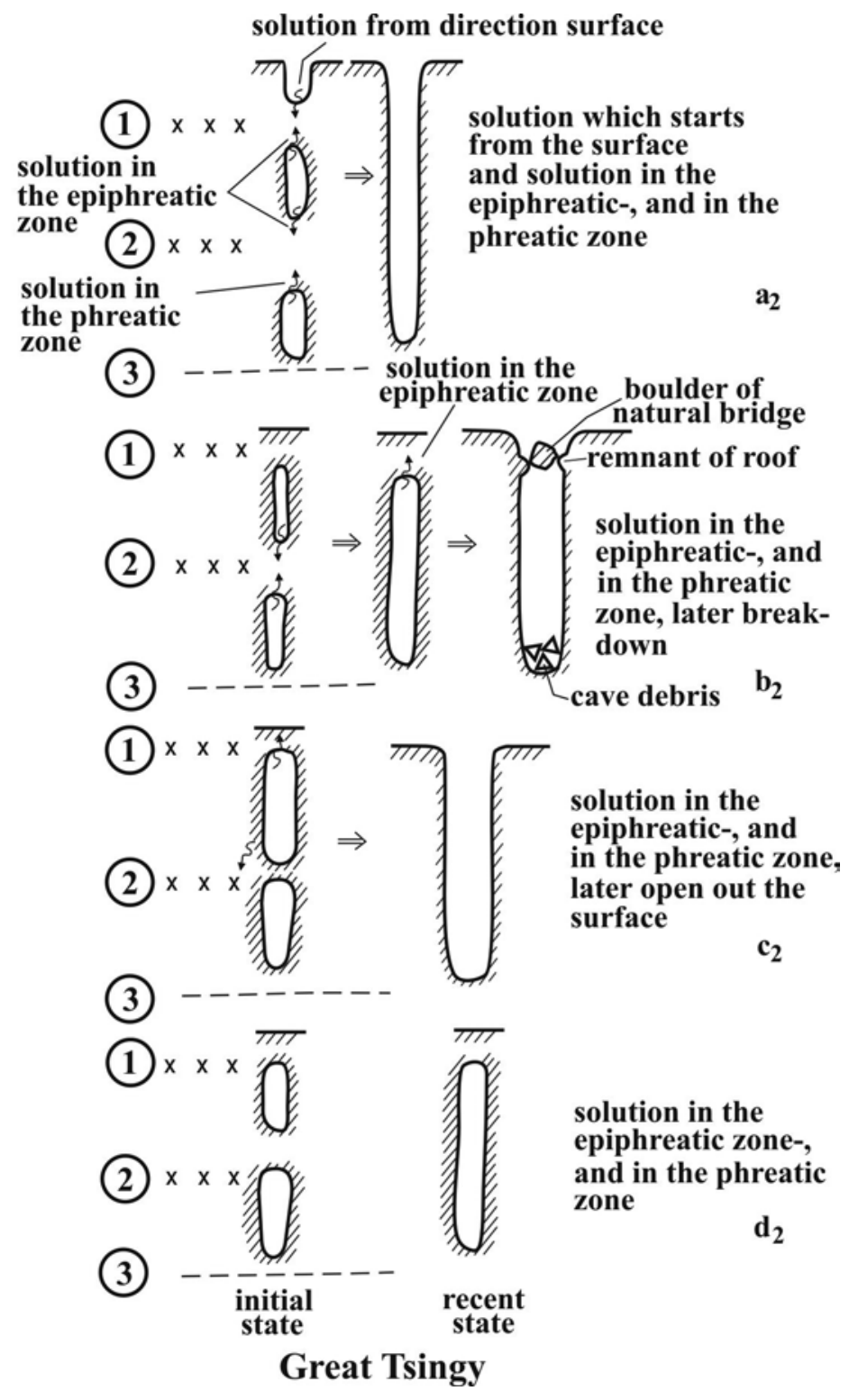

Fig. 19. Types of grike development (see text for explanation) 
phreatic zones but remained closed as the high karst water table was at relatively deep position below the surface (Fig. 19d $\mathrm{d}_{2}$ ).

The walls of the grikes are becoming gentler. We can prove this with the fact that the walls of the higher (and thus older) grikes show gentler slopes. This process may be caused by scarp retreat of the upper beds, promoted by the development of rillenkarren, the dissolution or fracturing of bedding scarps. The grike walls becomes more and more gentle because their walls are dissected by cup forms, pits, half pits and tributary grikes (Fig. 11). The remnants of the process will be pinnacles on the grike walls (Fig. 9).

\section{CONCLUSIONS}

Our observations show that the deep, downwards broadening and complex grikes of the Bemaraha tsingy could not have been formed by dissolution due to the action of surface waters. According to Delaty et al. (2006) the grikes of the tsingy developed when former caves were destroyed. We have found further evidence to support this theory. There are various options for the loss of cave roofs. The roof could collapse or the caves and the grikes (deepened from the surface) coalesced. The deepening of the grikes was probably due to rainwater or subsoil dissolution. The caves and the natural bridges of the tsingy are remnants of a former cave system which resulted from horizontal water flow. The cave network could develop because the River Manambolo was the base level of the karst are (as it is still today). Its water level is near the surface and it was even closer to the surface when the former cave network of the tsingy developed. The smaller grikes of the Bemaraha tsingy which do not widen downwards were produced by rainwater and subsoil dissolution.

\section{REFERENCES}

Balázs D., 1980 - Madagaszkár karsztvidékei (Karst areas on Madagascar). Karszt és Barlang, 1: 25-32.

Besairie H. \& Collignon M., 1972 - Géologie de Madagascar. I. Les terrains sédimentaires. Annales Géologiques de Madagascar, 35: $463 \mathrm{pp}$.

Bretz J H., 1956 - Caves of Missouri. Miss. Geol. Surv. and Water Resources, ser. 2: 39 p.

Cooke H. J., 1973 - A tropical karst in North-East Tanzania. Zeitschrift fur Geomorphologie, 17: 443-459.

Delaty J. N., Dobrilla J. C. \& Wolozan D., 2006 Observation concernant les Tsingy de Madagascar et plus particulièrement ceux de Bemaraha. Spelunca, 103: 39-44.

Dobrilla J. C., 2006 - Le massif karstique de Bemaraha. Spelunca, 102: 13-42.
Dobrilla J. C. \& Wolozan D., 1994 - Spéléologie sous les Tsingy de Bemaraha, Madagascar 1993. Etudes et Documents de I'ADEKS, 4: 1-62.

Duflos J., 1966 - Bilan des explorations biospéléologiques pour 1965. Madag. Rev. Géogr., 9: 235-252.

Ford D. C. \& Williams P. W., 1989 - Karst Geomorphology and Hydrology. Unwin Hyman, London, 601 pp.

Ford D. C. \& Williams P. W., 2007 - Karst Hydrogeology and Geomorphology. John Wiley \& Sons, Chichester, $562 \mathrm{pp}$.

Grimes K. G., 2008 - Tropical monsoon karren in Australia. Karst rock features, Karren sculpturing (in press).

Grunewald O. \& Wolozan D., 2006 - Tsingy. Stone forest - Madagascar. Editions Altus, 192 p.

Middleton G., 1996 - The 1995 Australo-Anglo-MalagasySpeleo-Ornitho-Malacological Expedition: Tsingy de Bemaraha, Western Madagascar. Journal of the Sydney Speleological Society, 40: 141-158.

Middleton G., 1998 - International Speleo-OrnithoGeo-Malacological Expedition: Northern Tsingy de Bemaraha, Western Madagascar. Journal of the Sydney Speleological Society, 42: 231-243.

Middleton G., 2004 - Madagascar. In: Gunn J., (Ed.) Encyclopedia of Caves and Karst Science. Taylor and Francis Books, New York. 493-495.

Renault Ph., 1968 - Contribution a l'étude des action mécanique et sédimentologiques dans la spéléogenèse. Annales de spéléologie, 23(3): 529-596.

Rossi G., 1974 - Morphologie et evolution d'un Karst en milieu tropical l'Ankarana. In: Phenomenes Karstiques II. Memoires et Documentes CRNS, 14: 279-298.

Rossi G., 1983 - Karst and structure in tropical areas: the Malagasy example. In: Paterson K. \& Sweeting M. M., (Eds.) - New directions in karst. Proceedings of the Anglo-French Karst Symposium (Geo Books, Norwich): 383-407.

Salomon J. N., 1987 - Le sudouest de Madagascar. Université D’Aix-en-Provence - Marseille, Marseille.

Salomon J. N., 2006 - Les tsingy et leur genèse. Spelunca, 103: 45-50.

SlabeT., 1995-CaveRockyRelief.Znanstvenaraziskovalni Center Sazu, Ljubljana: 128 pp.

Tricart J. \& Cardoso da Silva T., 1960 - Un exemple d'évolution karstique en milieu tropical sec: le morne de Bom Jesus dal apa. Zeitschrift fur Geomorphologie, 4: 27-42.

Verstappen H. Th., 1964 - Karst morphology of the Star Mountains, Central New Guinea. Zeitschrift fur Geomorphologie, 8: 40-49.

Wilford G. E. \& Wall J. R., 1965 - Karst topography in Sarawak. The Journal of Tropical Geography, 21: 4470 . 